\title{
La lengua española y las culturas hispánicas
}

\author{
Aurelio GonZÁLEZ \\ El Colegio de México
}

\begin{abstract}
Por número de hablantes nativos, el español es la segunda lengua del mundo. Es también la segunda lengua estudiada por número de alumnos. Y en aquellos lugares donde no es la lengua predominante, es una lengua prestigiada, con importancia en la expresión de una identidad y que trasmite valores culturales, económicos e ideológicos de amplio reconocimiento. En esta contribución se vuelve sobre algunos usos y valores asociados de la lengua española y las culturas hispánicas viendo en ellas elementos que unifican y construyen en el respeto de las diferencias una comunidad transnacional y panhispánica. La lengua, la cultura, la forma de pensar y actuar de los hombres y mujeres del mundo hispánico son el campo de ejercicio del pensamiento.
\end{abstract}

Keywords: español, lengua materna, lengua extranjera, plurilingüísmo, panhispanismo, identidades.

\section{La lengua española}

Como es bien sabido, por número de hablantes nativos, el español es la segunda lengua del mundo, 477 millones de personas la tienen como su lengua materna; en ella se comunican familiarmente, en ella crean artísticamente y en ella proyectan sus saberes, pero también en ella vierten sus sentimientos e ilusiones, en ella desarrollan un pensamiento crítico, en ella protestan y buscan mejorar y con ella se integran en una dimensión mayor que la expresión nacional o regional. A través de la lengua, esos millones de hablantes forman parte de un amplio y polifacético universo más amplio que su entorno local; ese universo es el mundo hispánico. El español es la lengua en la cual, sin perder lo particular, esos millones llegan a lo más amplio y general, y se establecen en un universo cultural que los enriquece rebasando los límites de lo regional.

Pero hay otro universo derivado también relacionado con la lengua, igualmente amplio, que no hay que perder de vista: hoy en día, en el mundo, el español es la segunda lengua estudiada por número de alumnos. En este momento, más de veinte millones de seres humanos son estudiantes

I Aurelio González (El Colegio de México. Presidente de la Asociación Internacional de Hispanistas), Presidente de mesa. Con la colaboración de Fausta Antonucci (Universidad Roma Tre, Italia. Presidenta de la Asociación de Hispanistas de Italia); Inger Enkvist (Universidad de Lund, Suecia); Pavel Stepánek (Universidad de Palacký de Olomouc y Universidad Carolina de Praga, República Checa); Robert Verdonk (Universidad de Amberes, Bélgica \& Director de la Cátedra Carlos V de Estudios Hispánicos); Susanne Zepp (Universidad Libre de Berlín, Alemania); Maja Zovko (Universidad de Zagreb, Croacia). 
de español en distintos grados. Así, casi seiscientos millones de personas (más precisamente, 572 millones) usan el español en todo el mundo. O sea, cien millones de personas que no son hablantes nativos la emplean en diferentes niveles y actividades, esto es, casi tantos hablantes como los que hay en México, el país con mayor número de hablantes de español (más de I20 millones).

Por otra parte, hay que tomar en cuenta que el español, en aquellos lugares donde no es la lengua predominante, no es una simple lengua subordinada de uso familiar entre grupos minoritarios, es una lengua prestigiada, con importancia en la expresión de una identidad y que trasmite valores culturales, económicos e ideológicos de amplio reconocimiento.

Además de por el número de hablantes, el español es importante por la presencia en los medios masivos de comunicación como internet, redes sociales, prensa, radio, televisión, etcétera, medios en los que su presencia es muy destacada, pero también hay que señalar que para el idioma español el ámbito en el que se estudia tiene un objetivo más amplio que el simple conocimiento de la lengua con fines de comunicación elemental o turismo; el estudio del español implica la aproximación a un universo cultural muy rico y con una larga trayectoria histórica, es el ámbito de lo hispánico y es en esta faceta que podemos identificar también este estudio como hispanismo, en el sentido más amplio del término, pues hispanismo no sólo es aquel que desarrolla el especialista académico de alto nivel.

El español funciona hoy en día, como es obvio, como el medio de comunicación de todos aquellos que son hablantes nativos y para los cuales es su patrimonio, pero también funciona como una lengua que porta valores identitarios y que, por tanto, es importante conservar y proyectar especialmente por aquellas comunidades que se encuentran insertas en otros ámbitos lingüísticos; por otra parte, el español es una lengua de servicio en la cual vierten sus trabajos y expresan sus conocimientos muchos millones de hablantes, pero también es una lengua de cultura, múltiple y variada, con una tradición multisecular. A la lengua española se acercan aquellos que la estudian con una gran variedad de intereses y cuando tiene un grado de dominio suficiente se integran, más allá de su objetivo inicial, en diversos niveles culturales, artísticos, económicos, laborales, comerciales o comunicativos de ese universo amplio que es el mundo hispánico.

\section{La lengua española: lo que unifica y construye comunidad}

Este mundo hispánico es múltiple, no en balde el español es la lengua de un país europeo y de diecinueve países americanos, además de que tiene amplia presencia en otros países como Estados Unidos, una presencia his- 
tórica, pero no por ello menos válida en Guinea o Filipinas, o trascendencia lingüístico-cultural como en el caso del sefardí.

En muchos casos, el español coexiste y vive con otras lenguas en el ámbito nacional, como es el caso de la misma España con el gallego, catalán o vasco, el guaraní en Paraguay, las distintas lenguas indígenas de amplia tradición en diversos países de América como el náhuatl, maya, quechua o aimara, o el inglés en Estados Unidos y el portugués en Brasil.

En cada país el español se puede hablar de manera distinta, usar cierto léxico, tener una entonación particular y giros propios y todo este conjunto se vuelve señas de identidad, pero luego, en la escritura, buena parte de todo ello se disuelve en una unidad cultural normativa más alta que no es la de ningún país sino la de todo el conjunto de países. Así, la lengua se integra de manera natural a la vida de una comunidad local, pero luego se proyecta y se integra en otra unidad supranacional que es el mundo hispánico que no cancela lo local, sino que lo proyecta como un conjunto en lo universal.

Como lengua, tenemos que el español es una expresión patrimonial de ámbito panhispánico, lo cual quiere decir que el español no es idéntico en todos los países donde se habla, sin embargo, a pesar de sus variedades, es una misma lengua y cumple con su función primordial que es la de permitir la comunicación. Por lo tanto, la lengua española es un elemento de unificación entre distintas comunidades que tienen distintos desarrollos, pero una misma raíz. Así, hay una comunidad supranacional que es la hispánica en la cual sus distintos elementos pueden tener diferentes sustratos más o menos amplios.

Si aceptamos la existencia de esta comunidad, entonces existe también un español panhispánico, que es el español que integra y acepta las múltiples variantes del uso de la lengua en los distintos países y regiones donde se habla y escribe.

No hay que olvidar que actualmente la realidad es que los hispanohablantes de distintas nacionalidades, sean españoles o hispanoamericanos o habitantes de los Estados Unidos se hacen entender entre sí y comprenden los valores asociados con la lengua a pesar de las múltiples variedades.

\section{La lengua española y sus valores asociados}

Probablemente uno de los valores asociados a la lengua española más importante sea la literatura, campo de estudio privilegiado del hispanismo internacional. En lo literario, por una parte, tenemos la tradición medieval de la cual surge la lengua española misma que está acompañada a lo largo de los siglos por monumentos literarios que se apoyan en la oralidad de la comunidad castellanoparlante. A esta lengua está asociada la épica del Cantar de mio Cid, el mester de juglaría de Gonzalo de Berceo, la profunda 
ambigüedad del Libro de buen amor del Arcipreste de Hita, el nuevo mundo que se viene para los caballeros al final de la Edad Media que se refuncionalizan en El conde Lucanor y sus extraordinarios cuentos, muchas veces originados en la cultura oral tradicional. Este periodo se cierra en lo literario con el extraordinario poder de la palabra dialéctica de la tragicomedia de la Celestina.

Pero el mundo medieval también marca el contacto con otras lenguas y la proyección del castellano. La conquista en I085 de Toledo y la tolerancia de los reyes castellanos hacia musulmanes y judíos facilitaron un intercambio cultural que permitió el renacimiento filosófico, teológico y científico primero de los reinos españoles y luego de todo el occidente cristiano. En el siglo XII la llamada Escuela de Traductores de Toledo implicó variados procesos de traducción e interpretación de textos clásicos grecolatinos, especialmente alejandrinos, que se pasaron del hebreo o del árabe al latín utilizando la lengua romance castellana como lengua intermedia, o incluso en otras ocasiones pasaron directamente a la lengua vulgar: el castellano en la cual se difundieron. Los textos que así se pudieron conocer fueron principalmente textos filosóficos y teológicos. Este proceso de contacto lingüístico es otro valor asociado al español.

Durante los siglos XVI y XVII, el esplendor literario, artístico y cultural de los Siglos de Oro, implica la gran literatura en lengua española de valor y proyección universal. Así, Don Quijote cabalga en español, Don Juan seduce en español, el teatro de Lope, Calderón Tirso de Molina o Ruiz de Alarcón llena las tablas universales del género dramático en español, y Góngora proyecta en español con alto vuelo el valor poético de la palabra. Y desde el otro lado del Atlántico la décima musa novohispana, Sor Juana, también canta al amor y reflexiona filosóficamente en español.

En el mundo contemporáneo la literatura en lengua española también es ámbito especial del hispanismo como lo es la de los Siglos de Oro, pero desde la revolución de la poesía de Rubén Darío en los albores del siglo xx, el universo hispánico de la lengua y la literatura como valor asociado tiene dos orillas, además de la tradicional peninsular y ahora brilla la americana. En España será la generación del 27 y en América las distintas vanguardias quienes se encargarán que resuene la poesía en español y los poetas españoles exiliados establecerán un puente con América uniendo las dos orillas. $\mathrm{Al}$ avanzar la segunda mitad del siglo xx la literatura en español se vuelve hispanoamericana en autores que hoy son universales como Gabriel García Márquez, Jorge Luis Borges, Octavio Paz, Julio Cortázar o Mario Vargas Llosa por citar sólo algunos nombres.

Hoy en día los medios de comunicación han incrementado los contactos entre las distintas comunidades hispánicas y hoy en día, la cultura, la literatura y la misma lengua son cada vez más panhispánicas y a ellas se 
aproximan con interés renovado los hispanistas tanto de los países hispanohablantes como los de otras latitudes.

\section{La comunidad ibérica a ambos lados del Atlántico}

Las dos orillas del mundo hispánico, con el Atlántico de por medio, forman un conjunto cuya riqueza está, entre otras facetas, en su variedad, la cual se refleja no sólo en su manera de hablar, sino también en su expresión, tradiciones y perspectivas vitales y, desde luego, patrimonio cultural.

En el continente americano se pueden distinguir regiones que engloban diversos países. En primer lugar, tendríamos Norteamérica en la cual estaría México, y en buena medida las colectividades de Estados Unidos (tanto las históricas como California, Nuevo México, Colorado, Texas o incluso Luisiana, como aquellas formadas por los movimientos migratorios recientes en Florida, Chicago o Nueva York); el Caribe insular: Cuba, República Dominicana y Puerto Rico; Centroamérica: integrada por Guatemala, El Salvador, Costa Rica, Nicaragua, Honduras y Panamá; la región de los Llanos: Venezuela y Colombia; El Pacífico: Perú, Chile y Ecuador; la zona andina: Bolivia y Paraguay; el Río de la Plata: Argentina y Uruguay.

El mundo hispánico no se puede comprender sin englobar estas dos orillas y su multiplicidad.

\section{Otros campos del saber explorados por hispanistas}

Al hablar del mundo hispánico y sus valores culturales, la reflexión no se puede limitar a aquellos relacionados directamente con la lengua como la literatura. Son muchos los campos de interés del hispanismo, en forma más cercana y directamente relacionados con la lengua son los estudios de literatura comparada y la traducción; gracias a la traducción al español el mundo hispánico se enriquece con horizontes culturales de otras lenguas, pero también cuando se traduce el mundo del español a otras lenguas se lleva la cultura y la manera de pensar, de vivir y de actuar del mundo hispánico a las colectividades de las lenguas a las que se traduce. El hispanista se acerca a la cultura de este mundo con el conocimiento de la lengua y por eso es un portador generoso entre los dos mundos.

Pero los intereses de conocimiento del hispanista desde luego que no se limitan al mundo de la lengua o a diversos aspectos relacionado con ésta, la historia, la sociología, el arte, el cine, la filosofía, en general la cultura visual o musical, son ámbitos en los cuales el hispanista investiga, busca y reconoce valores universales, valores comunes con otras culturas y destaca las peculiaridades y valores propios del mundo hispánico. 
El hispanismo se desarrolla en cada país distinto de los de mundo hispánico o de los que integran este mundo aportando numerosos elementos al conocimiento global de este polifacético mundo.

En este sentido, las asociaciones nacionales de hispanistas son muy importantes ya que colaboran a incrementar lo que se suele saber del mundo hispánico en los distintos países; cómo se entiende el hispanismo universitario y cómo se está trabajando en la situación de la enseñanza del español en los distintos países.

En el continente europeo, por ejemplo, se pueden citar, entre otras, la Association of Hispanists of Great Britain and Ireland (AHGBI), la Associazione Ispanisti Italiani (AISPI), la Deutscher Hispanistenverband (AAH), la Polskie Stowarzyszenie Hispanistów (PSH), la Sociedad Suiza de Estudios Hispánicos (SSEH), la Société des Hispanistes Français (SHF) y la Asociación de Hispanistas del Benelux (AHBx), que agrupa a los hispanistas de Bélgica, los Países Bajos y Luxemburgo.

Por lo general estas asociaciones sirven como punto de encuentro y enlace entre todas las personas y entidades relacionadas con el hispanismo, sobre todo dentro del ámbito universitario. Se dirige a hispanistas activos en cualquier disciplina o profesión: estudiantes y profesores de literatura, lingüística, historia, sociología, etc. igual que críticos, ensayistas, traductores y periodistas.

En otras ocasiones los hispanistas encabezan proyectos de investigación. Por ejemplo, en el hispanismo italiano, una línea de investigación tradicional, pero que en las dos últimas décadas ha cobrado especial fuerza es la de los estudios comparados hispanoitalianos: influencias y circulación de textos de España a Italia y al revés. Recientemente se ha creado un centro de estudios interuniversitario dedicado a las investigaciones hispanoitalianas en los siglos XV al XVII al que se adhieren más de veinte universidades, que reúne a hispanistas, italianistas e historiadores del teatro. La colaboración entre hispanistas y musicólogos en la investigación de la influencia española en los textos para la ópera italiana del siglo xvII es, desde hace diez años, intensa y fructífera. Una de las líneas de investigación del único proyecto nacional italiano financiado en la convocatoria de 2015 para el hispanismo es, precisamente, la profundización de las relaciones hispanoitalianas en lo que al teatro se refiere.

Por otra parte, en los tiempos actuales cuando términos como extraterritorialidad, transculturación, identidades fronterizas, entre otros, cobran más y más fuerza, el movimiento al interior del mundo hispánico es importante, por ejemplo, los autores hispanoamericanos que viven y publican en España y que conciben su literatura como una literatura en la frontera, prescindiendo de las barreras lingüísticas y optando por el uso indistinto de las diferentes variedades del español. Esta literatura plural 
responde a las dinámicas sociales de la actualidad y muestra la lengua española en toda su amplitud y la riqueza de sus variantes. Asimismo, está el caso de los autores de origen africano que escriben en español y contribuyen así a una mayor diversidad de voces y perspectivas en la literatura actual.

También es importante recordar el gran potencial antiesencialista de las literaturas y culturas hispánicas que se puede ilustrar con el ejemplo de las literaturas judías en lengua española. Tres perspectivas pueden servir para demostrar la importancia de este canon. Primero: las obras de este canon solo se entienden más allá de lo nacional. Esto también vale para representaciones binarias de Europa por una parte y de Hispanoamérica por otra. Segundo: los textos de este canon se desmarcan de los conceptos férreos de identidad - la religiosa, pero también la de género- a favor de una idea de pertenencia más allá del ejemplo concreto de las literaturas judías seculares. Tercero: los textos en sí mismos abren un espacio de conocimiento. Hoy, como en todos los momentos en que se han vivido grandes cambios sociales, deben historiarse los fenómenos culturales con más intensidad, enfocando la diversidad de las literaturas en lengua española como un recurso elemental para la capacidad del juico histórico, pero también para el discernimiento de la realidad social.

Otro campo de la cultura que se relaciona con el hispanismo en ámbitos no hispánicos es el de la historia del arte. No olvidemos que el primer libro de emblemas en español, con una muy importante iconografía, obra de Juan de Borja, fue publicado en Praga, en I58I. Además, el conocimiento de las formas históricas que contienen las obras plásticas en general, facilita la comprensión de muchos elementos históricos, incluso de descripciones literarias, la moda representada, hasta los gestos de las manos y posturas o el teatro, todos reflejos de la sociedad.

Las obras de arte implican en sí mismas influencias, en este caso hispánicas, en otros países, por ejemplo, reflejan la moda española difundida por toda Europa en el siglo xvi, que, en algunos territorios, como del Reino de Bohemia, hoy República Checa, se mantuvo más de un siglo.

Aparte del estudio general de la historia del arte español o hispanoamericano lo que se investiga con más detalle en esta área es la historia de las relaciones mutuas, pues, si por una parte se observan las influencias de España en otros países, por otra, se estudia la presencia de artistas de otros países, que ayudan a formar la cultura hispanoamericana. Como ejemplo están los checos Jun Rohr, cosmógrafo de Lima, o Simón Boruhradský (Simón de Castro) quien proyecta el palacio virreinal en la Ciudad de México.

También se puede hablar de un hispanismo que podemos llamar visual que en años recientes se potencia por un intercambio de exposiciones, artistas, etc. que indispensablemente va acompañado del idioma. 
El hispanista rastrea en la historia de la cultura de España y del mundo hispanoamericano los cambios y hechos, valores y circunstancias presentes a lo largo del tiempo que han conformado este mundo y los proyecta, en un gran ejercicio crítico del pensamiento; también señala los contactos de las corrientes artísticas y los artistas de su país con los del mundo hispánico e investiga las obras de la rica cultura plástica hispánica y la proyecta en otros ámbitos.

La lengua, la cultura, la forma de pensar y actuar de los hombres y mujeres del mundo hispánico son el campo de ejercicio de pensamiento del hispanista y los proyecta a través de la lengua española. 